\title{
The significance of traceability in consumer decision making towards Karoo lamb
}

\author{
Henriëtta J du Plessis and Gerrie E. du Rand \\ Department of Consumer Sciences. University of Pretoria, South Africa \\ Author for correspondence: Henriëtta du Plessis \\ E-mail: henrietta.duplessis@tuks.co.za
}

\begin{abstract}
As food markets have become more globalised, consumers have become more concerned about the origin of the foods they eat with a decreased confidence in the quality and safety of foods produced outside their local region or country. Traceability systems address this concerns and the importance of establishing a link between a product, producer and place of production has therefore gained momentum as a trend.
\end{abstract}

This paper describes the product attributes that influence the decision making process of consumers towards purchasing Karoo lamb. Karoo lamb is lamb that is specifically reared in the Karoo region of South Africa and has a distinctive taste. The information used in this paper was obtained in the first phase from three focus groups that were conducted to identify the product attributes that were critical in affecting the consumers' preferences and choices regarding the product (lamb). In phase two conjoint analysis was used to measure the importance individual consumers attach to the different levels of the various product attributes and the utility they then attached based on their valuation of the complete product.

Price as an extrinsic attribute was the most important factor in the decision making process of consumers when purchasing lamb. Safety and quality were also relatively important with food safety clearly an important consideration to consumers when buying meat. This is not surprising given the legacy of BSE and e-coli outbreaks that were given a lot of publicity in the press in the past. The origin attribute was however rated as of the lowest importance.

Traceability can be meaningful to consumers but primarily in an indirect manner as the importance of traceability to consumers is in terms of its benefits such as safety and quality, 
in relation to aspects that they think are important regarding food in general. In the area for meat there is a need for fast and reliable systems to enable traceability along the full supply chain to provide safe and high quality food for the consumer as the end user with respect to origin.

Keywords: conjoint analysis, consumer decision making, traceability, Karoo lamb, place of origin

\section{INTRODUCTION}

Food markets have become more globalised with the result that consumers have become more concerned about the origin of the foods they eat and are becoming more enthusiastic about high quality food with a clear regional identity. By nature food products are land based and therefore have a regional or geographic origin, but the link between food and territory has eroded over time. Karoo lamb is a product with specific regional qualities that are based on, among others, the natural environment present in the region of origin. Together with the specific product qualities, regional image factors create a unique identity for a product, as in the case of Karoo lamb and in this way bring about added value. Consumers will only consume food products that fulfill their specific demand requirements and have become more demanding about what they want.

Consumers face various competitor products in their purchase choice and their purchasing decision is based on several attributes or cues such as price, functional characteristics, external appearance, guarantee, brand or designation of origin. With respect to traceability characteristics, tracking meat products focuses on two types of characteristics: functional characteristics (such as organizational efficiency and meat chain monitoring) and process characteristics (such as origin and production methods).

A heightened awareness of food-related safety issues among today's food consumers is driving the demand for more information about the vertical food supply chain and specifically, the origin and handling of food products generated and consumed throughout the world (Smith, Tatum, Belk, Scanga, Grandin \& Sofos, 2005). Food traceability systems per se guarantee nothing except the ability to track the product throughout the food chain (Verbeke, 2001). However it is considered to be indispensable in assuring product safety for consumers and for implementing quality standards, for delivering wholesome products to end-consumers and reliable information and feedback throughout the livestock production 
chain (Verbeke, W \& Vackier, I. 2004). Through traceability the benchmark for standard products are raised. In the case of Karoo lamb traceability can be considered as a buying and confidence criterion especially when it is taken as an information provider of the origin, the producer and the ingredient, high quality lamb meat.

In regard to the traceability of food, three questions arise: Firstly, whether traceability is in itself of value or valued by consumers. Secondly, whether consumers associate additional attributes for instance safety and quality with traceability and thirdly whether consumers are willing to absorb the increased costs of traceability to retailers.

\section{BACKGROUND}

\subsection{The product - Karoo lamb}

The Karoo covers almost $50 \%$ of the total area of South Africa. This semi-arid area stretches North-eastwards from the Cape and is covered with flat dry scrubland. The area has very low grazing capacity and the natural pasture for the lamb varies from mixed grass and shrub veldt to Karoo shrub veldt. It can be argued that the particular taste of Karoo lamb is the result of the animals foraging on the fragrant Karoo shrubs or that the distinctive taste results from the free-range conditions under which the animals roam (Kirsten, Troskie, Vermeulen, Schonfeldt \& Bramley, 2008). Karoo lamb is marketed straight from the veldt and no additional feed is provided as the animal will then lose its particular taste.

The problem however arises that there is a lack of certification and guarantee that the product, which is marketed as Karoo Lamb, truly originates from the Karoo and consumers can easily be misled as to the true origin of the lamb being sold.

The following practices can be used to certify lamb or mutton originating from the Karoo. It includes specific practices to ensure the unique characteristics of the final product, Karoo lamb.

- Only animals originating from the Karoo or animals that remain in the area of the Karoo as defined, at least 12 months before slaughter and which are free of scheduled diseases should be used.

- Animals should have free access to natural veldt grazing and may have additional but simultaneous free access to farm feeds containing cereals, silage or any other natural plant matter. 


\subsection{Consumer decision making process towards lamb}

Every day consumers make numerous decisions concerning every aspect of their daily lives. A decision can be described as the selection of an option from two or more alternative choices. Consumer decision making can be explained with a consumer decision model that specifies various stages of the consumer decision making process. Within the consumer decision making perspective, purchase is considered as one point in a particular course of action undertaken by a consumer. In order to understand that ultimate point, examination of preceding events, such as problem recognition, the search and processing of information and the evaluation of product alternatives, is needed. A model is simply a means of describing a concept, its causes and its effects. Models also provide us with a framework for analyzing consumer behaviour.

Without recognition of a problem, there is no need for a decision. When a consumer has the intention to buy lamb but is unsure about the quality and safety a need arises to rectify the situation. The consumer will start searching for information that has the potential to assist in fulfilling this need of purchasing good quality, safe lamb meat. Two prepurchase search processes are distinguished: internal and external. During the internal search, consumers search for information within their own memory. The image of the Karoo will probably bring to mind for consumer's pictures of windmills, sheep, endless pastures and thoughts of wholesomeness, tradition and quality. Past experience is considered an internal source of information. Availability and accessibility of product information (e.g., product name, attributes and benefits) are necessary conditions for this information to be retrieved from memory. Having consumed a certain type of lamb and found it a pleasurable experience the memory will assist in future decision making. If this information is perceived insufficient for a purchasing decision an external search for information may follow for instance examining advertisements. The information obtained during the external search leads to an internal search for interpretation and/or elaboration (Van Ittersum, 2002). Consumer information needs and the management of information are particularly challenging because there are so many product attributes to provide information about and because consumers and their needs differ.

Traceability systems represent the most suitable tool for circulating information on product quality to end consumers and for making the whole supply chain more transparent (Bertolini, Bevilacqua \& Massini, 2006). The consumer has to decide upon the criteria on which the alternatives are evaluated and has to integrate the perceptions of the alternatives on those criteria into an overall attitude about the attractiveness of each product alternative. The type 
of food product determines the criteria used by a consumer and the criteria used for meat products will differ from that used for dairy products. Consumer decision is the outcome of evaluation and involves the mental process of selecting the most desirable alternative from a set of options that a consumer has generated.

\subsection{Food attributes as influencing factors}

A consumer receives information (cues) on product attributes during shopping and consuming. Cues may be learned by inspecting and consuming the product and the cues are used by the consumer to evaluate the performance of the product with respect to his/her needs.

Traceability is defined as the ability to maintain a credible custody of identification for animals through various steps within the food chain from the farm to the retailer. Traceability of a food consists of development of "an information trail that follows the food product's physical trail" (Smith, et al., 2005). It guarantees the immediate recall of food and feed, if applicable, in case of need. In the meat sector traceability holds that it is a system that offers the ability to identify an animal, trace its movement throughout its life and subsequently trace the meat products of the animal to the final consumer (Verbeke, 2001). As a result specific food quality and safety levels can be guaranteed and in fact the words transparent and assurance can be interchanged with traceability.

Coff, Korthals \& Barling (2008) classify five "objectives of traceability in food":

- Risk management and food safety;

- Control and verification;

- Supply chain management and efficiency;

- Provenance and quality assurance of products;

- Information and communication to the consumer.

Traceability can be an important tool to help to establish the authenticity of food and to check that claims made by producers are true (Van Rijswijk, W., Frewer, L.J., Menozzi, D. \& Faioli, G. 2008). Traceability is a credence characteristic. Consumers can not recognize before or after purchase of the product, whether there is a guarantee that the product is actually traceable but have to trust the information provided by the retailer. In the differentiation of a product of animal origin many of the desired attributes are introduced at the production level and cannot be added during processing. In the case of Karoo lamb consumers can be 
misled as to the true origin of the lamb being sold and the reputation and image of the product, Karoo lamb has the danger of being usurped. Currently there is no certification and guarantee that the product, which is marketed as Karoo lamb, truly originates from the Karoo. Indeed traceability may be utilised to back up product claims such as origin and quality labeling.

Quality. The concept of product quality can be analysed under two main different perspectives: the objective quality and the perceived quality. Objective quality refers to the technical, measurable and verifiable quality of products/services, processes and quality controls. Subjective or perceived quality refers to the consumers' value judgments or perceptions of quality (Espejel, Fandos \& Flavian, 2007). The concept of perceived quality can further be classified in two groups of factors that allow the consumers to evaluate the products: intrinsic attributes and extrinsic attributes (Espejel, et.al., 2007). In South Africa meat quality is managed by means of a meat classification system based on animal age, carcass fat content and conformation.

Quality perceptions of meat have traditionally been based on intrinsic cues like the colour of the meat, the visible fat and the cut because fresh meat is largely an unbranded product (Grunert, 2006). Quality and safety are part of the intangible characteristics of a food product and helps to give more value to the product and to differentiate it. Traceability is an essential tool for ensuring both production and product quality and the opportunity to connect traceability with the whole documentation and control system represents an effective means for boosting the consumer's perception of a food's safety and quality (Bertolini, et al., 2006).

Safety. Among the world's food industries, the meat industry is the one facing most public negativity, especially due to the association of meat consumption with certain risks to human health (heart disease) and secondly safety scares. The main risks related to meat consumption as perceived by consumers are chemical residues of growth hormones and antibiotics, high fat content and the related hazard of increased cholesterol, microbial infections (salmonella, Escherichia coli), dioxins and the resulting danger of food poisoning, use of genetic modification in the production of animal feed as well as BSE. Consumers are thus starting to look for signs and certification that guarantee safety and reassure them. Traceability is generally viewed as a potential risk management tool for public health purposes as it enables consumers to be provided with targeted and accurate information concerning products. 
Origin. All agricultural products have specific geographic origins. Consumers differentiate between products from different countries or areas, a phenomenon known as the country-oforigin effect. This effect is rooted in the image the consumer has of the quality of specific products, to the point where consumers use origin as a cue for determining product quality, either alone or in conjunction with other product information. The importance of foods associated with a particular locale can be attributed to the climate and geomorphology of the region and the resultant local resources such as water and the indigenous crops (Kuznesof, Tregear \& Moxey, 1997). This will give the product its distinctive taste namely the flavour of the area. In the case of the Karoo a selection of six key plants were selected that are the most common and contribute according to folklore the most to the specific taste of the Karoo. These grazing plants from the Karoo and Karoo-like regions can impact herbal and musty attributes to mutton meat from sheep breeds of these regions and distinguish the lamb/mutton meat as meat-of-origin. This gives the product certain unique characteristics that are not repeatable elsewhere.

\section{RESEARCH AIMS AND OBJECTIVES}

The aim of this study is to explore traceability as a system as it relates to a product of origin, specifically Karoo lamb and the influence thereof on consumers decision making process when selecting/purchasing Karoo lamb. The following specific objectives and sub objectives are set for this study: The primary objective of this study was to determine and describe the product attributes that influences consumers purchasing decision of Karoo lamb. The secondary research objectives were to determine consumers' valuation of key attributes that influence their purchasing decision of mutton/lamb and to determine and describe the different levels of importance of the product attributes that influences the purchasing decision of consumers regarding Karoo lamb. In addressing these objectives quantitative and qualitative research methods were considered useful in obtaining rich descriptive data.

\section{RESEARCH DESIGN}

\subsection{Research population/Sample}

Although the South African consumer population is very diverse, most if not all South African consumers engage in some form of food purchasing. To research the whole population would require time and funding. Therefore one can select a subgroup from the whole group to examine. For the purpose of this study, participant criteria were kept to the minimum with 
the intention of recruiting a heterogeneous sample of lamb meat purchasing consumers that included males and females from different income groups and different age ranges.

To ensure that the sample provided valid information that could be referred to the larger population, participants were selected by means of a convenient selection method but according to the pre determined criteria. Respondents were solicited from the database of the marketing firm Consulta based in Centurion that is located in the province of Gauteng, South Africa as the conjoint experiment was conducted electronically. A total number of 1011 electronic questionnaires were distributed to individual consumers that varied as to age, sex, nationality, wealth, social status etc. When determining the sample size the researcher decides how many elements will be a part of the sample. To receive reliable and valid data the sample size must be well thought off, though it does not guarantee unbiased results since these can be affected by other parts of the research process. It was not necessary in this study to compare groups to each other but rather to focus on individual respondents.

\subsection{Data collection}

Three different data collection methods were used: semi-structured interviews, focus group discussions and conjoint analysis. When opting to use conjoint analysis to measure consumer preferences, one of the first steps is to establish the attributes and attribute levels to be incorporated into the analysis. If the wrong attributes are selected an incorrect understanding of consumer decision making and an invalid measurement of the values which consumers attach to the decision factors will be gained. There are several techniques for identifying product attributes and attribute levels relevant to consumers in their decision making. These include interviews and focus group discussions.

\subsection{Qualitative study methodology}

The qualitative phase was used to help define the attributes and levels for the conjoint design. The preliminary attributes and levels for use in the conjoint study were derived through initial field interviews with industry experts and decision makers involved in the procurement, use and supply of red meat to the retail industry. 


\subsection{Semi structures interviews}

During the end of 2008 and the beginning of 2009 semi-structured interviews were conducted with role-players in the red meat industry (South African Meat Industry Council and technologists of different retailers) with the purpose of getting an overview of the stance of the red meat industry and the implementation of traceability in the supply chain, the so called farm to fork continuum. For this reason the semi-structured interviews were carefully analysed. It was established that the different retailers in South Africa that sell lamb/mutton have different traceability processes in place and that the information is considered highly confidential by all the retailers.

\subsection{Focus group discussions}

Focus group discussions can be defined as carefully planned discussions designed to obtain perceptions on a defined area of interest in a permissive, non-threatening environment (Kuznesof, et al., 1997). It is a special kind of interview that is very useful in exploratory research (Neuman, 1997 \& Bless \& Higson-Smith, 1995). It can also be said that is a technique involving the use of in-depth group interviews in which participants are selected because they are a purposive, although not necessary representive sampling of a specific population, this group being 'focused' on a given topic (Rabiee, 2004).

One of the distinct features of focus group interviews is its group dynamics, hence the type and range of data generated through the social interaction of the group are often deeper and richer than those obtained from one-to-one interviews (Rabiee, 2004). Focus groups can provide information about a range of ideas and feelings that individuals have about certain issues, as well as illuminating the differences in perspective between groups of individuals. Focus groups can generate large amounts of data in a relatively short time span and the findings may be used to precede quantitative procedures (Rabiee, 2004).

A qualitative type of research, in particular, the use of focus groups was considered the most appropriate for some of the objectives of this study. While a thorough literature review was used to provide a theoretical framework for the study, the focus group discussions allowed for inclusion of additional information that might not have been taken into consideration. The focus group discussions were mainly held firstly to develop an indication of the existing understanding, knowledge levels and awareness of South African consumers regarding Karoo lamb linked to its geographical origin and secondly to determine the product attributes that influence the purchasing decision of consumers regarding Karoo lamb. 
Each focus group was composed of a maximum of ten participants, sufficient to provide diversity of perceptions without being unwieldy. Three group sessions were facilitated and scheduled based on the availability of participants. Focus group interviews generate large amounts of data. Content analysis was used as a data analysis technique as it is a technique for gathering and analysing the content of text.

\subsection{Quantitative study methodology}

Two criteria were taken into consideration in order to select the Karoo lamb product attributes for the conjoint experiment. The selected Karoo lamb attributes must be critical in affecting consumers purchasing decision regarding the product and it must be able to influence the selected product attributes according to the research objectives of the conjoint analysis experiment. In this conjoint experiment the product attributes were determined by means of focus group discussions, by considering possible secondary information sources and by taking the research objectives into account. Table 1 shows the attributes with the attribute levels.

Having established the relevant attributes and their levels, hypothetical scenarios with different combinations of attributes that defined the product were presented to the participants.

\subsection{Conjoint analysis}

Conjoint analysis requires that a hypothetical product be described to the participants in the study along with the attributes and attribute levels that define the product. This allows for part worth utilities or a partial utility score for each level of an attribute. Respondents are then asked to rank several hypothetical products as defined by different combinations of attribute levels (Hair, J.E., Black, W.C., Babin, B.J., Anderson, R.E. \& Parham, R.L. 2006). In such a simulated market experiment consumers are faced with choices similar to those they would face making any purchase decision. The attributes traceability, quality, safety, origin and price were used in the experiment and while other attributes could have been included, it was necessary to weigh the number of attributes required to realistically represent the product against the need to simplify the representation so as not to complicate the respondent's task needlessly. The attribute levels were determined based on the levels that consumers might realistically face. The levels defined for traceability for instance were trace to animal, trace to birth farm, trace to abattoir, and no trace. 
The total possible number of scenarios is equal to the product of the number of selected product attributes and the number of selected attribute levels and can result in numerous possible scenarios. In the study the number of attribute level combinations was calculated as 3600 due to $5 \times 4 \times 4 \times 5 \times 9=3600$. Clearly it would have been unrealistic to ask individuals their preferences for so many scenarios and it would have been unfeasible for the researcher to draw conclusions of the choices made by the respondents. The full factorial design that uses all levels of factors and leading to many profiles were not suitable to be used. Instead a fractional factorial design was generated to reduce the number of experimental scenarios that were presented to the respondents. To solve this problem an orthogonal design was applied by using the Statistic Package for the Social Sciences (SPSS). An orthogonal design generator is a part of SPSS that combines different levels of attributes and generates a lower number of questions that are needed to perform a full analysis.

Once the set of hypothetical lamb meat products was designed the questionnaire was presented to consumers in an electronic format. In ratings-based conjoint analysis product concepts can be shown to respondents one at a time or they can be presented in pairs. Pair-wise presentation can be harder for the respondent because each question requires understanding two concepts rather than just one. However, the comparative nature of the pair-wise task may let the respondent make finer distinctions and contribute more information than single concept (popularly called card sort) presentation. Pair-wise presentation is also particularly useful for computer administrated conjoint questionnaires.

Conjoint analysis is a type of thought experiment, rather than a data analysis procedure. It models the nature of consumer trade-offs amongst multi-attribute products or services. The method measures the importance individual consumers attach to various product attributes and the utility that consumers attach to the different levels of the various attributes, based on their valuation of the complete product. By forcing consumers to make trade-offs between products, it mimics their actual behavior when purchasing products, thus preferences are revealed through a series of rating or trade-offs decisions. Thus, conjoint analysis enables the researcher to identity the attribute combinations that confer the highest level of utility to the consumer and to establish the relative importance of attributes in terms of their contribution to the total utility derived by the specific respondent.

Consumers do not consider each attribute of a food product singly and independently when making a purchasing decision. Instead they consider the whole range of product attributes 
in totality (Koo, L.C., Tao, F.K.C. \& Yeung, J.H.C. 1999). When asked to do so outright, many consumers are unable to accurately determine the relative importance that they place on product attributes.

The theory and methods of conjoint analysis deal with complex decision making, or the process of assessment, comparison and/or evaluation. In this process consumers decide which aspects of products or services are important, compare the products or services on each of the important aspects, and decide which one to choose (North \& de Vos, 2002).

\subsection{Data analysis}

The qualitative nature of the first part of the study resulted in a large amount of raw data, which needed to be analysed in a manner that would conserve the rich and descriptive value of the collected data. Accordingly, all the recorded focus group discussions and semistructured interviews were first transcribed verbatim to ensure that the transcriptions remained true to the phenomenological nature of the data. All comments were listed and the transcripts became part of the data used for analysis.

The data from the quantitative study, the conjoint experiment was processed using Sawtooth Software to determine conjoint part-worths within each attribute and conjoint importances for the attributes relative to one another were assessed. The analysis was carried out at the individual level and consolidated to total levels. Tables and graphs were used to support the findings of the research. Once the conjoint had been designed and the attributes and levels determined, the data were analysed in three basic steps:

- Calculation of the relative attribute importance to determine the importance of attributes in the consumer decision making process towards Karoo lamb

- Calculation of the level of importance of each relevant attribute for the product Karoo lamb

- Preparation of the attribute simulation tool and product simulations

\subsection{Trustworthiness}

Strategies to ensure the trustworthiness of the data and results were derived from strategies described by authors such as Babbie and Mouton (2007) and Leedy (2009). These strategies were focused on ensuring credibility, dependability, transferability and conformability of the study. Criteria specific to each of these aspects were applied. A control of literature on decision-making was performed to ensure credibility of findings. 
Triangulation, another criterion for credibility was accomplished through the use of three different data collection methods. Semi-structured interviews, three focus group discussions and a conjoint analysis experiment were completed to find support for the concepts and themes identified and to ensure that data saturation was achieved. Additional criteria for credibility included reflexibility (field notes were made during data-collection sessions and subjected to analysis) and member checks (field notes were discussed with participants to ensure the notes corresponded with their opinions).

A detailed description of the research methodology allowed for the transferability and dependability of the study. For transferability purposes, specific details pertaining to the selection of the sample were highlighted. The use of various data collection methods and more specifically, consistency in the application of these capturing methods (such as the use of the same question guide for each participant) contributed to the dependability of the study. All records and transcripts were kept and audited by the researcher for the purposes of conformability.

\section{FINDINGS AND INTERPRETATION}

A total of 1011 questionnaires were distributed electronically with the help of the marketing firm Consulta in October - November 2009 and 608 completed questionnaires were returned to Consulta. This is a response rate of $60.14 \%$. In total 352 completed questionnaires that met the criteria or $34.9 \%$ of the questionnaires were used in the data analysis. The buying and/or consuming of lamb/sheep were the only criteria that needed be met to be part of the conjoint survey.

Green \& Srinivasan (1978) stated that conjoint analysis is essentially an analysis of consumer responses for a number of product attributes organized to an experimental design pattern. The results from the experiment were analysed in SPSS, using the conjoint analysis procedure. In order to run a conjoint analysis the software SPSS is required and the analysis is made with syntaxes. CVA features a variety of options and functionalities. The calculation routines can be used to analyse questionnaire data and calculate respondent utilities.

Thus the results of the analysis were able to indicate what combinations of attribute levels were ranked highest and the relative importance of each attribute and attribute level because in real life consumers may find it difficult to indicate which attribute they consider of value 
and how they combine the attributes to form their overall opinion. If the most preferable product is not feasible for some reason then the conjoint analysis will identify the next most preferable alternative.

The CVA program creates an index score out of 100 (a percentage) to indicate an attribute's importance. When the outcomes of the analysis were interpreted, it was found that the impact of price on the purchasing decision was $30.4 \%$ and thus price was the most important attribute in the determination of the consumer choice. There are three possible reasons for the reluctance by consumers to pay an increased price for the attribute traceability: Firstly consumers increasingly have concerns about food products but not at the levels at which they would be willing to pay extra. Secondly consumers do not think that traceability is sufficient to guarantee food safety or quality and thirdly consumers regard food traceability as a basic obligation from producers and retailers and thus feel no obligation to pay a price premium for it.

Price is often known to be one of the most important and determining factors in the consumer's decision making process. A higher price can sometimes symbolize through the price better quality or safety of the product for the consumers. Therefore paying a higher price can be seen as paying for a meat product that has better quality. Safety is the second most important attribute after price and it was found effective in the purchasing decision at $23.1 \%$. The third attribute affecting purchasing decision was quality. Quality attribute affects this decision with $17.0 \%$. The fourth attribute of traceability affects purchasing decision with $15.7 \%$ and the importance of the fifth attribute, origin was $13.8 \%$.

In figure 1 the relative importance of each individual attribute is shown graphically.

In evaluating products, consumers will always make trade-offs. A consumer may like the quality and safety feature of a particular product like Karoo lamb, but reject the purchase due to the cost. In this case, cost has a high utility value. Utility can be defined as a number which represents the value that consumers place on an attribute. In other words, it represents the relative "worth" of the attribute. A low utility indicates less value and a high utility indicates more value. The attribute level, which has the highest part-worth, is the most preferable alternative by consumers. In conjoint analysis, the difference between attribute levels as much as the part-worth of every attribute level represents the impact of regarding attributes on consumer preferences. In the present study the attribute importance and partworth or weighted utility values of attribute levels were calculated per individual for each of the selected scenarios. 
The utility values for each attribute level are determined within an arbitrary additive constant, which means that a utility level from one attribute cannot be compared to the utility level from another attribute (Orne, 2006). Therefore, the negative utility values for price have no significant relation in comparison to the utility values of the other attributes. Every utility value should therefore be compared within its own attribute. The utility values for each attribute level are shown in table .

As can be seen from table 1 the respondents have the greatest preference for lamb meat that can be traced back to the birth farm. The second most preferred level is lamb meat traced back to the abattoir and the least preferred is lamb meat that cannot be traced. Traceability to the birth farm, abattoir and processing plant have positive utility levels while traceability to the animal and no traceability have negative utility values. Further, the respondents have the greatest preference for lamb meat that originates from a specific region the Karoo. This is followed by the level local region, then national region and lastly preferred is the lamb meat with no specific region. According to the utility values for quality, the respondents strongly preferred the lamb meat with quality through certification. This is clearly shown by the utility value 0,089 . The second most preferred is for lamb meat with quality through origin, then followed quality through labeling/branding and least preferred is lamb meat with quality that is not assured. The utility values for safety shown that the respondents preferred lamb meat with safety through certification, followed by safety through place of purchase with a utility value of 0,144 and then safety through labeling/branding. The last two levels for safety, safety not guaranteed and no safety knowledge are both negative and do not vary much. The utility values for price indicated that the respondents clearly preferred the price level $7.5 \%$ less for the lamb meat, followed closely by the price level $5 \%$ less. The least preferred is the price level $10 \%$ more for the lamb meat. Table 2 is a summary of each attribute with the attribute level and the level of importance.

\section{Simulation findings}

In addition to providing information on the importance of product features, conjoint analysis provides the opportunity to conduct computer choice simulations. This function is one of the main reasons why conjoint analysis is used. It is the final stage in the conjoint analysis process. Simulation analysis models are used to estimate choice share (a surrogate for market share) based on respondent preferences for different "simulated products" each of which is defined by specifying a select set of attribute levels. Looking only at average preferences (part worth utilities) can mask important market forces caused by patterns of 
preference at the segment of individual level. Marketers are often not interested in averages but in the targetable, idiosyncratic behavior of segments or individuals.

The simulator is used to convert raw conjoint (part worth utility) data into something much more managerially useful: simulated market choices. Products can be introduced within a simulated market scenario and the simulator reports the percent of respondents projected to choose each. Simulators simply use a rule for tabulating votes for the product concepts being tested in the simulator. The objective of the simulator is to create a "market environment" that tests preferences between options being tested. Knowing how important or valuable each profile is can be useful when wanting to know the best combination. The results of market simulators are easy to interpret because they are scaled from zero to one hundred. And, unlike part-worth utilities, simulation results (shares of preference) are assumed to have ratio scale properties - it is legitimate to claim that a $40 \%$ share of preference is twice as much as a $20 \%$ share. Sensitivity analysis using market simulation offers a way to report preference scores for each level of each product attribute.

The sensitivity analysis approach can show us how much we can approve (or make worse) a product's overall preference by changing its attribute level one at a time, while holding all other attributes constant at base case levels. The market simulation is run repeatedly to capture the incremental effect of each attribute level upon product choice. After all the levels were tested within a given attribute that attribute is returned to its base case level prior to testing another attribute.

'What if' simulations can thus be modeled and answers obtained from the simulation. Conjoint simulators are directional indicators, which can provide much information about the relative importance of features and preferences for products. With the simulation tool the researcher was able to test alternative product scenarios as illustrated in tables 1 and 2 . Various simulations can be run by changing the levels to find the optimum importance and preference of each profile.

Table 3 illustrates two simulations based on assumptions made specifically for the product Karoo lamb.

Table 3 indicates that the profile score obtained from simulation 1 is higher than that of simulation 2. Two attribute levels, namely 'trace to birth farm' and 'same price' were similar in both simulations. 
One can now change the levels for a specific attribute category and see the potential impact of the change. The price attribute level is changed in simulation 3 from 'same price' to 'price $5 \%$ more'. Table 4 illustrates the effect of change on the simulation and indicates that consumers are extremely price sensitive.

As indicated in Table 4 the profile score obtained from simulation 3 is now lower than that of simulation 4. The tool therefore indicates that the product Karoo lamb as simulated in simulation 4 is valued higher $(86.1 \%)$ as the product in simulation 3 and has gained a higher preference among the participants.

\section{CONCLUSIONS}

Conclusions were based on the quantitative and qualitative data findings of the study. A consumer perspective was used as the point of departure. For this research the electronic conjoint analysis survey was the principle method of data collection. However to gain background information for the conjoint analysis survey three focus group discussions were held as well as semi structured interviews with role players in the meat industry. The analysis of the data and interpretation of the results were done in accordance with the objectives set for the study.

Although the study was bound in time and place it does not change the importance of the insights gained. Conjoint analysis consists of planning and implementing experiments among consumers in order to model the consumer purchasing decision and to understand which factors create value for the consumer. Conjoint analysis embodies more than seven major phases. It starts by selecting the product attributes and finishes with stating the relative importance of different attributes of a product to a consumer. Conjoint analysis has been quite useful as a market research and analysis tool for a variety of consumer goods where it is most widely used in marketing analysis and product development applications but has also begun to be used for a variety of agricultural products. The outcomes of this conjoint analysis study provide not only useful information about the importance of traceability in general but also provided additional information about the relative importance (i.e., utility) of information about various product characteristics such as region of origin, traceability, safety and quality that might be associated with a particular meat product, Karoo lamb.

The focal attribute in the study was traceability. Price was included in the study because it is one of the most important product attributes when purchasing food. In conjoint analysis 
participants indicate their preference for a series of hypothetical multi-attribute alternatives, which are typically displayed as profiles of attributes. The responses to these profiles are analysed to yield estimates of the relative importance of the attributes. The basic aim, therefore, is to determine the features that consumers most prefer. Thus the results of the analysis are able to indicate what combinations of attribute levels are ranked highest and the relative importance of each attribute and attribute level because in real life consumers may find it difficult to indicate which attribute they consider of value and how they combine the attributes to form their overall opinion. If the most preferable product is not feasible for some reason then the conjoint analysis will identify the next most preferable alternative. When the outcomes of the analysis were interpreted, it was found that price is the most important attribute in determination of the consumer choice. This is the case regardless of biological sex, age, education, culture or product knowledge. The CVA program creates an index score out of 100 (a percentage) to indicate an attribute's importance. The results have shown that the impact of price on purchasing decision was $30.4 \%$. Price is often known to be one of the most important and determining factors in the consumer's decision making process. A higher price can sometimes symbolize through the price better quality or safety of the product for the consumers. Therefore paying a higher price can be seen as paying for a meat product that has better quality. Safety is the second most important attribute after price and it was found effective in the purchasing decision at $23.1 \%$. The third attribute affecting purchasing decision was quality. Quality attribute affects this decision with $17.0 \%$. The fourth attribute of traceability affects purchasing decision with $15.7 \%$ and the importance of the fifth attribute of origin was $13.8 \%$.

In evaluating products, consumers will always make trade-offs. A consumer may like the quality and safety feature of a particular product like Karoo lamb, but reject the purchase due to the cost. In this case, cost has a high utility value. Utility can be defined as a number which represents the value that consumers place on an attribute. In other words, it represents the relative "worth" of the attribute. A low utility indicates less value and a high utility indicates more value. The attribute level, which has the highest part-worth, is the most preferable alternative by consumers. In conjoint analysis, the difference between attribute levels as much as the part-worth of every attribute level represents the impact of regarding attributes on consumer preferences. In the present study the attribute importance and partworth or weighted utility values of attribute levels were calculated per individual for each of the selected scenarios.

The results show that the respondents have the greatest preference for lamb meat that can be traced back to the birth farm. The second most preferred level was lamb meat traced 
back to the abattoir and the least preferred was lamb meat that cannot be traced. Traceability to the birth farm, abattoir and processing plant have positive utility levels while traceability to the animal and no traceability have negative utility values. Further, the respondents have the greatest preference for lamb meat that originates from a specific region the Karoo. This was followed by the level local region, then national region and lastly preferred was the lamb meat with no specific region. According to the utility values for quality, the respondents strongly preferred the lamb meat with quality through certification. The second most preferred was for lamb meat with quality guaranteed through origin, then followed quality through labeling/branding and least preferred was lamb meat with quality that was not assured. The utility values for safety shown that the respondents preferred lamb meat with safety through certification, followed by safety through place of purchase with a utility value of 0,144 and then safety through labeling/branding. The last two levels for safety, safety not guaranteed and no safety knowledge were both negative and do not vary much. The utility values for price indicated that the respondents clearly preferred the price level $7.5 \%$ less for the lamb meat, followed closely by the price level $5 \%$ less. The least preferred was the price level $10 \%$ more for the lamb meat.

In addition to providing information on the importance of product features, conjoint analysis provides the opportunity to conduct computer choice simulations. The simulator is used to convert raw conjoint (part worth utility) data into something much more managerially useful: simulated market choices. Products can be introduced within a simulated market scenario and the simulator reports the percent of respondents projected to choose each.

\section{References}

Babbie, E. \& Mouton, J. 2007. Practice of Social Research. South African Edition. Cape Town. Oxford University Press.

Bertoloni, M., Bevilacqua, M., \& Massini, R. 2006. FMECA approach to product traceability in the food industry. Food Control (17):137-145.

Bless, C. \& Higson-Smith, C. 1995. Social Research Methods. $2^{\text {nd }}$ Ed. Juta.

Coff, C., Korthals, M. \& Barling, D. 2008. "Ethical traceability and informed food choice" in Coff, C., Barling, D., Korthals, M. \& Nielsen, T. (Eds). Ethical Traceability and Communicating Food: The International Library of Environmental, Agricultural and Food Ethics (15):1-22. 
Espejel, J., Fandos, C. \& Flavian, C. 2007. The role of intrinsic and extrinsic quality attributes on consumer behavior for traditional products. Managing Service Quality 17(6):681-701.

Green, P.E. \& Srinivasan, V. 1978. Conjoint analysis in consumer research: issues and outlook. Journal of Consumer Research (5):103-123.

Grunert, K.G. 2006. Future trends and consumer lifestyles with regard to meat consumption. Meat Science (74):149-160.

Hair, J.E., Black, W.C., Babin, B.J., Anderson, R.E. \& Parham, R.L. 2006. Multi variate data analysis. Pearson Prentice Hall, Upper Sadle River, NJ.

Kirsten, J., Troskie, D., Vermeulen, H., Schonfeldt, H. \& Bramley, C. 2008. The potential for Karoo Lamb as origin based meat and a Geographical Indication. Research report. Department of Agricultural Economics and Rural Development. University of Pretoria. South Africa.

Koo, L.C., Tao. F.K.C. \& Yeung, J.H.C. 1999. Preferential segmentation of restaurant attributes through conjoint analysis. International Journal of Contemporary Hospitality Management 11(5):242-250.

Kuznesof, S., Tregear, A. \& Moxey, A. 1997. Regional foods: A consumer perspective. British Food Journal 99(6):199-206.

Leedy, P.D. \& Jeanne, E. 2009. Practical Research Planning and Design.

Neuman, W.L. 1997. Social research methods. $3^{\text {rd }}$ Ed. Boston. Allyn \& Bacon.

North, E. \& De Vos, R. 2002. The use of conjoint analysis to determine consumer buying preferences: A literature review. Journal of Family Ecology and Consumer Sciences (30):32-39.

Orme. 2006. Conjoint Analysis: Using a market based research model for health care decision making. 
Rabiee, F. 2004. Focus-group interview and data analysis. Proceedings of the Nutrition Society (63):655-660.

Smith, G.C, Tatum, J.D, Belk, K.E, Scanga, J.A, Grandin, T. \& Sofos, J.N. 2005.

Traceability from a US perspective. Meat science (71):174-193.

Van Ittersum, K. 2002. The role of region of origin in consumer decision making and choice. Mansholt Graduate School of Social Sciences. Wageningen. The Netherlands.

Van Rijswijk, W., Frewer, L.J., Menozzi, D. \& Faioli, G. 2008. Consumer perceptions of traceability: A cross-national comparison of the associated benefits. Food Quality \& Preference (19):452-464.

Verbeke, W. 2001. The emerging role of traceability and information in demand-oriented livestock production. Outlook on Agriculture 30(4):249-255.

Verbeke, W. \& Vackier, I. 2004. Profile and effects of consumer involvement in fresh meat. Meat Science (67):159-168.

\section{Legends for the figures}

Figure 1: Relative importance of each product attribute

\section{Legends for the tables}

Table 1: Product attributes and attribute levels

Table 2: Attribute relative importance

Table 3: Attribute simulation tool for Karoo lamb - example one

Table 4: Attribute simulation tool for Karoo lamb - example two 
Table 1: Product attributes and attribute levels

\begin{tabular}{|l|l|}
\hline \multicolumn{1}{|c|}{ Attributes } & \multicolumn{1}{|c|}{ Attribute levels } \\
\hline Traceability & Trace to animal \\
& Trace to birth farm \\
& Trace to abattoir \\
& Trace to processing plant \\
& No trace \\
\hline Origin & Origin: Local region \\
& Origin: National (SA) \\
& Origin: No region \\
& Origin: Specific region (Karoo) \\
\hline Quality & Quality through certification \\
& Quality through labeling/branding \\
& Quality through origin \\
& Quality not assured \\
\hline Safety & Safety through certification \\
& Safety through labeling/branding \\
& Safety through place of purchase \\
& Safety not guaranteed \\
& No safety knowledge \\
\hline Price & $10 \%$ more \\
& $7.5 \%$ more \\
& $5 \%$ more \\
& $2.5 \%$ more \\
& Same price \\
& $2.5 \%$ less \\
& $5 \%$ less \\
& $7.5 \%$ less \\
& $10 \%$ less \\
\hline
\end{tabular}


Table 2: Attribute relative importance

\begin{tabular}{|l|l|c|c|}
\hline \multicolumn{1}{|c|}{ Attribute } & \multicolumn{1}{|c|}{ Attribute levels } & $\begin{array}{c}\text { Attribute relative } \\
\text { importance (\%) }\end{array}$ & $\begin{array}{c}\text { Attribute level } \\
\text { utility value }\end{array}$ \\
\hline 1. Traceability & Trace to animal & 15.7 & -0.001 \\
& Trace to birth farm & & 0.075 \\
& Trace to abattoir & & 0.031 \\
& Trace to processing plant & & 0.001 \\
& No trace & & -0.106 \\
\hline 2. Origin & Origin: Local region & 13.8 & 0.003 \\
& Origin: National (SA) region & & -0.052 \\
& Origin: No region & & -0.070 \\
& Origin: Specific region (Karoo) & & 0.118 \\
\hline 3. Quality & Quality through certification & 17 & 0.089 \\
& Quality through labeling/branding & & 0.049 \\
& Quality through origin & 0.054 \\
& Quality not assured & & -0.193 \\
\hline 4. Safety & Safety through certification & & 0.162 \\
& Safety through labeling/branding & & 0.063 \\
& Safety through place of purchase & & 0.144 \\
& Safety not guaranteed & & -0.181 \\
& No safety knowledge & & -0.188 \\
\hline 5. Price & 10\% more & & -0.118 \\
& 7.5\% more & & -0.103 \\
& 5\% more & & -0.084 \\
& 2.5\% more & & -0.036 \\
& Same price & & -0.033 \\
& 2.5\% less & & 0.040 \\
& 5\% less & & 0.135 \\
& 7.5\% less & & 0.138 \\
& 10\% less & & 0.061 \\
\hline
\end{tabular}


Table 3: Attribute simulation tool for Karoo lamb - example one

\begin{tabular}{|l|l|l|}
\hline \multicolumn{1}{|c|}{ Base Case } & \multicolumn{1}{c|}{ Simulation 1 } & \multicolumn{1}{c|}{ Simulation 2 } \\
\hline No trace & Trace to birth farm & Trace to birth farm \\
\hline Origin: No region & Origin specific region Karoo & Origin local region \\
\hline Quality not assured & Quality through origin & Quality not assured \\
\hline No safety knowledge & No safety knowledge & Safety through place of purchase \\
\hline Same price & Same price & Same price \\
\hline \multicolumn{1}{|c|}{-} & $\mathbf{8 2 . 4 \%}$ & $\mathbf{8 1 . 8 \%}$ \\
\hline
\end{tabular}

Table 4: Attribute simulation tool for Karoo lamb - example two

\begin{tabular}{|l|l|l|}
\hline \multicolumn{1}{|c|}{ Base Case } & \multicolumn{1}{c|}{ Simulation 3 } & \multicolumn{1}{c|}{ Simulation 4 } \\
\hline No trace & Trace to birth farm & Trace to birth farm \\
\hline Origin: No region & Origin specific region Karoo & Origin specific region Karoo \\
\hline Quality not assured & Quality not assured & Quality not assured \\
\hline No safety knowledge & Safety through place of purchase & Safety through place of purchase \\
\hline Same price & Price 5\% more & Same price \\
\hline \multicolumn{1}{|c|}{} & $\mathbf{8 0 . 1 \%}$ & $\mathbf{8 6 . 1 \%}$ \\
\hline
\end{tabular}


Figure 1: Relative importance of each product attribute

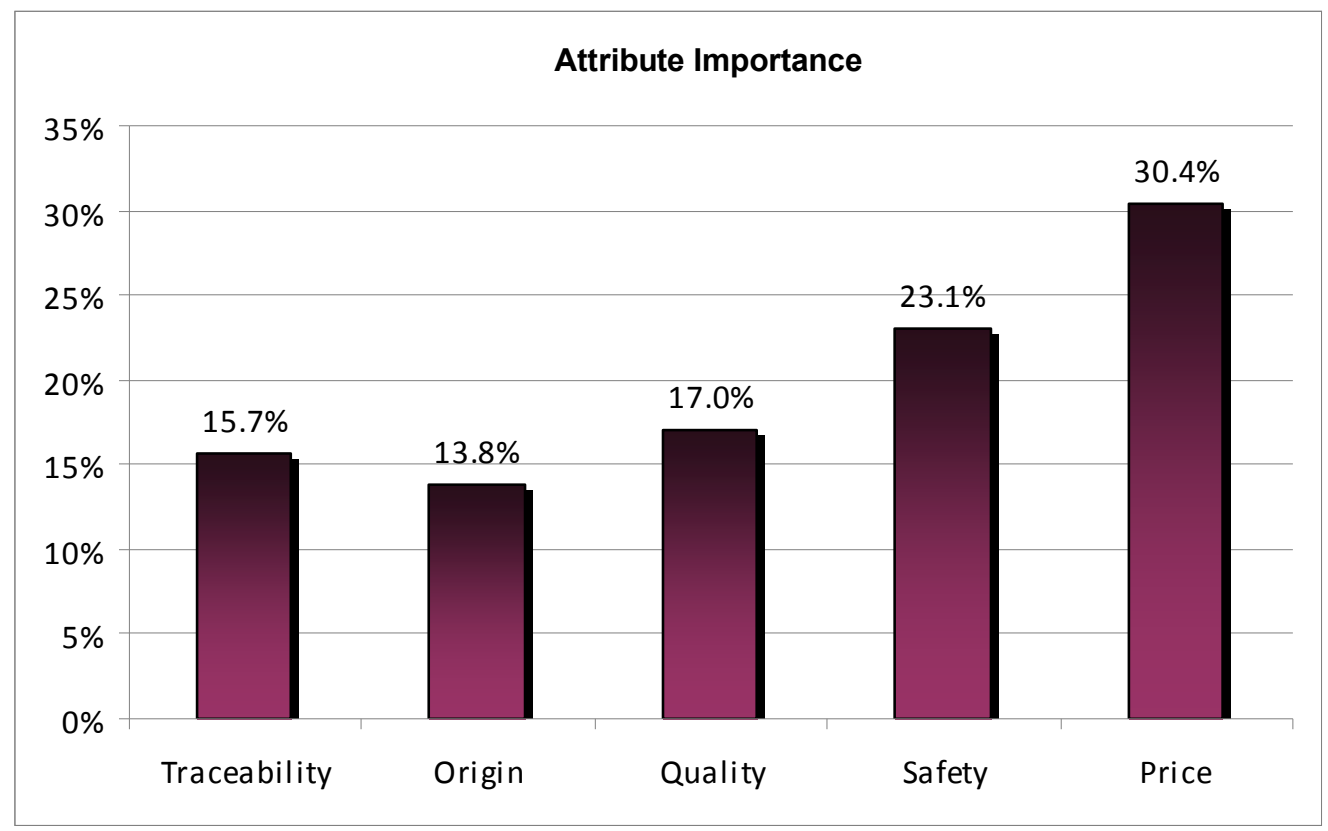

